\title{
Corrigendum: Comparative Pharmacokinetics of Meloxicam Between Healthy Post-partum vs. Mid-lactation Dairy Cattle
}

\author{
Rochelle Warner ${ }^{1}$, Joshua A. Ydstie ${ }^{1}$, Larry W. Wulf ${ }^{2}$, Ronette Gehring ${ }^{3}$, \\ Johann F. Coetzee ${ }^{4}$, Jonathan P. Mochel ${ }^{1,5}$ and Patrick J. Gorden ${ }^{1 *}$ \\ ${ }^{1}$ Department of Veterinary Diagnostic and Production Animal Medicine, lowa State University College of Veterinary Medicine, \\ Ames, IA, United States, ${ }^{2}$ Analytical Chemistry Section, Veterinary Diagnostic Laboratory, lowa State University College of \\ Veterinary Medicine, Ames, IA, United States, ${ }^{3}$ Veterinary Pharmacotherapy and Pharmacy, Department of Population Health \\ Sciences, Utrecht University, Utrecht, Netherlands, ${ }^{4}$ Department of Anatomy and Physiology, Kansas State University \\ College of Veterinary Medicine, Manhattan, KS, United States, ${ }^{5}$ SMART Pharmacology, Department of Biomedical Sciences, \\ Iowa State University College of Veterinary Medicine, Ames, IA, United States
}

Keywords: meloxicam, pharmacokinetics, post-partum, NSAID, dairy

\section{A Corrigendum on}

Comparative Pharmacokinetics of Meloxicam Between Healthy Post-partum vs. Mid-lactation Dairy Cattle

\section{OPEN ACCESS}

Edited and reviewed by:

Arturo Anadón,

Complutense University of Madrid, Spain

*Correspondence:

Patrick J. Gorden

pgorden@iastate.edu

Specialty section: This article was submitted to Veterinary Pharmacology and Toxicology

a section of the journal Frontiers in Veterinary Science

Received: 06 February 2021 Accepted: 04 May 2021

Published: 26 May 2021

Citation:

Warner R, Ydstie JA, Wulf LW Gehring R, Coetzee JF, Mochel JP and Gorden PJ (2021) Corrigendum: Comparative Pharmacokinetics of

Meloxicam Between Healthy

Post-partum vs. Mid-lactation Dairy Cattle. Front. Vet. Sci. 8:665021. doi: 10.3389/fvets.2021.665021 by Warner, R., Ydstie, J. A., Wulf, L. W., Gehring, R., Coetzee, J. F., Mochel, J. P., et al. (2020). Front. Vet. Sci. 7:548. doi: 10.3389/fvets.2020.00548

In the original article, there was a mistake in the legend for Tables 2 and $\mathbf{4}$ as published. In these tables, the number of cows in each group were stated incorrectly. The correct legend appears below.

Table 2. Plasma concentrations $(\mu \mathrm{g} / \mathrm{mL})$ for meloxicam from seven post-partum cows compared to five mid-lactation cows that received intravenous administration of a single dose of meloxicam at $0.2 \mathrm{mg} / \mathrm{kg}$. Results are presented as geometric means and 95\% confidence interval.

Table 4. Plasma pharmacokinetic parameters for meloxicam from seven post-partum cows compared to five mid-lactation cows intravenously administered a single dose of meloxicam at 0.2 $\mathrm{mg} / \mathrm{kg}$. Results are presented in geometric means and $95 \%$ confidence intervals. $P$-values are based on non-parametric Wilcoxon Rank Sums 2-sample normal approximation.

In the original article, there was a mistake in Table 4 as published. In this table, the units for $\mathrm{V}_{\mathrm{d}}$ should have been $\mathrm{L} / \mathrm{kg}$. The corrected Table 4 appears below.

In the original article, there was a mistake in Table 5 as published. In this table, the units for $V_{Z} / F$ should have been $\mathrm{L} / \mathrm{kg}$ and the values for $V_{Z} / F$ were incorrectly reported as $\mathrm{mL} / \mathrm{kg}$. The corrected Table 5 appears below.

The authors apologize for this error and state that this does not change the scientific conclusions of the article in any way. The original article has been updated.

Copyright $\odot 2021$ Warner, Ydstie, Wulf, Gehring, Coetzee, Mochel and Gorden. This is an open-access article distributed under the terms of the Creative Commons Attribution License (CC BY). The use, distribution or reproduction in other forums is permitted, provided the original author(s) and the copyright owner(s) are credited and that the original publication in this journal is cited, in accordance with accepted academic practice. No use, distribution or reproduction is permitted which does not comply with these terms. 
TABLE 4 | Plasma pharmacokinetic parameters for meloxicam from seven post-partum cows compared to five mid-lactation cows intravenously administered a single dose of meloxicam at $0.2 \mathrm{mg} / \mathrm{kg}$.

\begin{tabular}{lccc}
\hline IV & Mid-lactation & Post-partum & P-value \\
\hline$C_{\max }(\mu \mathrm{g} / \mathrm{mL})$ & $1.22(0.92-1.55)$ & $1.06(0.84-1.34)$ & 0.26 \\
$T_{\max }(\mathrm{h})$ & $0.13(0.08-0.19)$ & $0.23(0.08-4.01)$ & 0.73 \\
$\mathrm{~V}_{d}(\mathrm{~L} / \mathrm{kg})$ & $0.29(0.24-0.35)$ & $0.31(0.19-0.48)$ & 0.94 \\
$\mathrm{CL}(\mathrm{L} / \mathrm{kg} / \mathrm{h})$ & $0.03(0.02-0.03)$ & $0.01(0.009-0.02)$ & 0.009 \\
$A \cup C_{\infty}(\mathrm{h} \times \mu \mathrm{g} / \mathrm{mL})$ & $8.26(6.62-10.10)$ & $16.30(6.18-31.75)$ & 0.009 \\
$A \cup C_{\%}$ extrapolated & $1.65(1.29-2.06)$ & $1.68(-11.13-29.84)$ & 0.14 \\
$\lambda_{z}\left(\mathrm{~h}^{-1}\right)$ & $0.08(0.08-0.09)$ & $0.04(0.03-0.07)$ & 0.006 \\
$A \cup M C_{\infty}(\mathrm{h} \times \mu \mathrm{g} / \mathrm{mL})$ & $93.33(72.00-118.95)$ & $24.16(12.23-85.36)$ & 0.009 \\
$\mathrm{MRT} T_{\infty}(\mathrm{h})$ & $11.30(10.44-12.19)$ & $17.31(8.59-64.05)$ & 0.006 \\
$T_{1 / 2}(\mathrm{~h})$ & $8.23(7.90-8.58)$ & $0.004(0.003-0.006)$ & 0.006 \\
$\mathrm{E}$ & $0.008(0.006-0.01)$ & 0.009
\end{tabular}

Results are presented in geometric means and 95\% confidence intervals. P-values are based on non-parametric Wilcoxon Rank Sums 2-sample normal approximation.

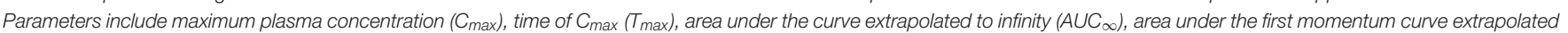

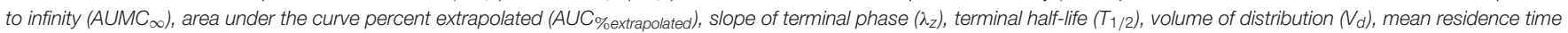
$\left(M R T_{\infty}\right)$, and clearance $(C L)$.

TABLE 5 | Plasma pharmacokinetic parameters for meloxicam from six post-partum cows matched to mid-lactation cows orally administered a single dose of meloxicam at $1.0 \mathrm{mg} / \mathrm{kg}$.

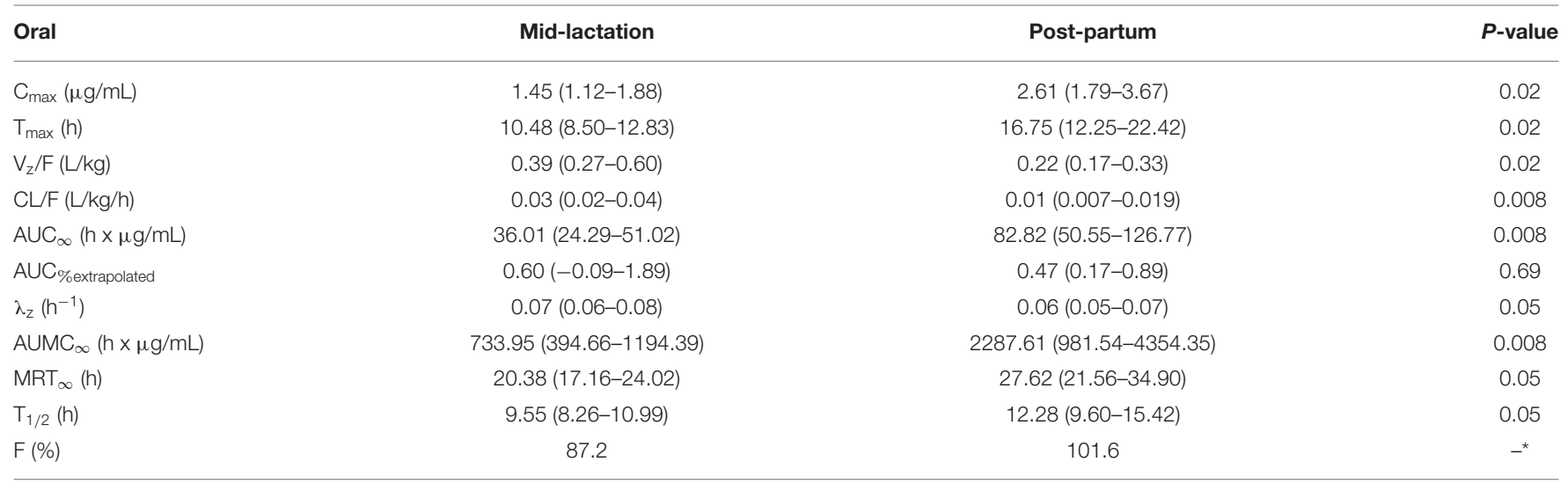

Results are presented in geometric means and range. P-values are based on non-parametric Wilcoxon Rank Sums 2-sample normal approximation.

Parameters include maximum plasma concentration $\left(C_{\max }\right)$, time of $C_{\max }\left(T_{\max }\right)$, area under the curve extrapolated to infinity $\left(A \cup C_{\infty}\right)$, area under the curve percent extrapolated $\left(A \cup C_{\%}\right.$ extrapolated), area under the first momentum curve to infinity $\left(A \cup M C_{\infty}\right)$, slope of terminal phase $\left(\lambda_{z}\right)$, terminal half-life $\left(T_{1 / 2}\right)$, volume of distribution per fraction of drug absorbed $\left.N_{Z} / F\right)$, mean residence time (MRT $\left.\infty\right)$, clearance per fraction of drug absorbed (CL/F), and absolute bioavailability ( $\left.F_{a b s}\right)$.

${ }^{*}$ Statistical comparisons could not be made between treatment groups due individual animals receiving a single treatment and therefore clearance cannot be assumed to be consistent. 